\title{
Analysis on the risk control of ecological chain for E-commerce system in online shopping mall
}

\author{
Li Yang, Wenjie Zhou, Yingzhao He \\ College of business, North West Normal University, Lanzhou, Gansu, China
}

\begin{abstract}
With the example of online shopping mall, the risk and risk control scheme of ecological chain for E-commerce system is analyzed in the paper. The risks are estimated, analyzed and solved gradually based on the risk management theory, thus exploring the new scheme for the healthy development of online shopping mall.
\end{abstract}

Keywords: E-commerce, Online shopping mall, Risk control

\section{Introduction}

Internet was gradually popularized in the late 1990s, and E-commerce industry based on Internet was put on the stage officially, which made E-commerce become a systematic discipline system rapidly.[1] Along with the rapid development of E-commerce and the huge reform in the world brought by the wide application, a kind of fresh management theory-E-commerce management theory was formed, and the more thorough, broader and far-reaching reform than any revolution in history was brought by the development of E-commerce.[2] Its vitality is powerful extremely for the development of E-commerce is established based on the high-tech and means, while it also has the shortcomings and limitations as other fresh things, and it is confronted with the obstacles to be overcome. Therefore, the major transformation will occur on the business philosophy and management mode of E-commerce in the near future.

The ecological theory has sublimated into the science theory on epistemology in contemporary economic society, permeated into the levels of social economy and been noted by the researchers from many disciplines. [3] The domestic scholars only analyzed the E-commerce as the market economy activity at first. In recent years, the information management scholars have begun to introduce ecological theory into the E-commerce, analyzed the chained mode among E-commerce subjects, and discussed the mechanism and evolution process of ecological chain for E-commerce. It is vital to apply the risk management theory from the management theory on the research of ecological chain for E-commerce because of the inevitable risks among E-commerce activities. It has been very mature of the risk management theory in our country, the domestic government agencies, small and medium enterprises have conducted the effective resource management with the risk management theory, and used the risk management measures to reduce the risk loss.

\section{Analysis on the ecological chain of E-commerce system}

E-commerce product suppliers, E-commerce service providers and E-commerce product consumers are included in the subjects of ecological chain for Tmall E-commerce, wherein the service providers refer to Jingdong Mall information website, Alipay, WeChat 
and other E-commerce payment platforms and logistics platforms; the suppliers include Jingdong self-support producers and third-party suppliers; the consumers include the ordinary users, government agencies and enterprises and other users. The E-commerce ecological chain with certain length and width is formed among the subjects, and the operation process is shown in Figure 1.

The goods manufacturers and suppliers release E-commerce information on the sales system of the website

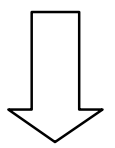

Consumers get the goods information via logging in the website

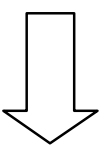

Consumers select the payment way and distribution way and the goods order is generated
A series of E-commerce activities are completed

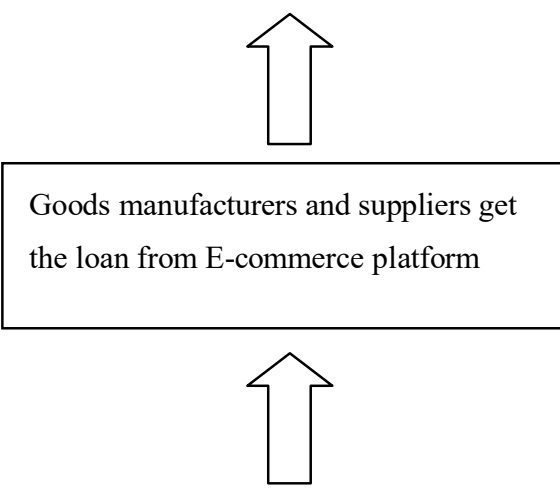

E-commerce platform issues the loan information to the website

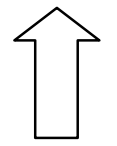

Consumers confirm the receiving and complete the evaluation after the goods

are confirmed without error

Service providers distribute the goods according to the shipment address of the order

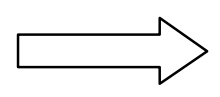

Figure 1 Operating process of ecological chain system for E-commerce

\section{Main risks of ecological chain for E-commerce system}

The main risks at the key link shall be analyzed and evaluated according to the risk management theory after the operating process of ecological chain for Jingdong E-commerce is combed. The risk factors among four kinds of risk manifestations of ecological chain for Jingdong E-commerce are listed in the following to lay the foundation for the analysis of risk source and the formulation of risk strategy later.

Firstly is the structural fracture risk with the manifestation that the dependence relationship is lost among the suppliers, service providers or consumers, the amount of users buying the produced products is gradually decreased, and even it is more difficult to sell. Certain party selects to withdraw for E-commerce service network, payment platform and logistics platform do not cooperate with the supplier or the cooperation cost is too large.

Secondly is operating paralysis risk with the manifestation that the suppliers can not provide the products at the reasonable amount, huge goods have the situation of no inventory and it can not meet the consumers' demands on the product, the consumers can not buy the 
needed goods, or there is some problems on the quality of the product, and the inventory backlog and others are caused by the severe return later.

Thirdly is the organizational aging risk with the manifestation that the aging risk of ecological chain is formed by the slow distribution time of goods logistics, wrong information environment and payment environment in Jingdong mall, management mode and node combined aging.

Fourthly is the negative image risk with the manifestation of poor reputation on the goods from the consumers, excessive expansion of product chain in Jingdong with the purpose of profit.

The reasons and risk sources for the main risks in the ecological chain of Jingdong E-commerce are cleared according to the above figure combined with the analysis of main risks and the manifestations, thus catching the fundamental problem and providing the preliminary idea to solve the problem.

\section{Basic idea to control the risk of E-commerce system}

The risks existed in the operating process of ecological chain of Jingdong E-commerce are mainly caused by the technical equipment, service level, consumption tendency, market competition and others, the manifestations of structural fracture of ecological chain, operation paralysis, internal organizational aging and external image and other risks occur. The risks are managed targeted from two directions of risk prevention and risk control combined with the technology, asset, node combination, service level and supplier after the key points of the problem are cleared based on these risk manifestations linked with the analysis of risk reason and risk source.

Control the quality strictly to reduce the risk

The ecological chain of Jingdong E-commerce strictly controls the quality of the product provided by the suppliers, the standardized auditing system is established for the entering goods, and the risks for the cooperation parties are reduced via auditing standard and counterfeit penalty term and other measures. The quality of self-support products is controlled strictly, the service quality of E-commerce website for Jingdong Mall is improved, the enthusiasm of the service personnel is cultivated to improve the service efficiency effectively, the positive reply is made according to the user's evaluation, thus guaranteeing the users' satisfaction and improving the users' viscosity consumption ability. Many logistics standby nodes are set in the whole country for the ecological chain of Jingdong E-commerce, starting the standby node under the short-term paralysis can guarantee the accurate distribution of E-commerce products to the consumers.

Share the liability transferring risk jointly

The third party sellers are also included in the suppliers of ecological chain of Jingdong E-commerce in addition to the self-support sellers of Jingdong after 2010, empowerment sharing risk within the chain requires the ecological chain of Jingdong E-commerce to share the risks with other sellers. For example, Mobil oil announced officially the statement that the false oil was sold in Jingdong Mall in 2014, Jingdong released soon and admitted the product quality problem, the third party suppliers accepted the money compensation, public apology and removing from the shelves and even exited from the ecological chain of Jingdong E-commerce and others. The sharing risk is one of transferring processing strategies of ecological chain for E-commerce.

Improve the technology to avoid the risk 
Jingdong set the global shopping in 2015, thus increasing the nodes of ecological chain, enlarging the width of ecological chain correspondingly, and also bringing the huge pressure for the technology and asset cost. Meanwhile, the cross-border E-commerce is faced with the policy, exchange rate, tariff, integrity and other unstable factors. The corresponding information technology and logistics technology shall be improved when exploring the overseas market to obtain the users' loyalty and preference information. Concerning the product type, the specific product and service are sold with the standard of overseas consumers' preference.

\section{Conclusion}

The risk problem in the ecological chain of E-commerce is discussed combined with multiple discipline theories with the research object of E-commerce activity subjects in the ecological chain of E-commerce and the chain dependence relationship among the E-commerce subjects.

\section{Reference}

[1] Chiu C M, Wang E T G, Fang Y H, et al. Understanding customers' repeat purchase intentions in $\mathrm{B} 2 \mathrm{C}$ e - commerce: the roles of utilitarian value, hedonic value and perceived risk[J]. Information Systems Journal, 2014, 24(1): 85-114.

[2] Lin X, Featherman M, Brooks S L, et al. Exploring Gender Differences in Online Consumer Purchase Decision Making: An Online Product Presentation Perspective[J]. Information Systems Frontiers, 2018: 1-15.

[3] Han T, Yoo B, Jeon S. Building a Korean fashion platform in Taobao, China's biggest online commerce: The case of fashion e-commerce company Accommate[J]. Seoul Journal of Business, 2015, 21(1): 87. 